\title{
Hydrotropic Study on Furfural - Comprehensive Design Expert Plot
}

\author{
C.Jaya Kumar \& N. Nagendra Gandhi \\ Department of Chemical Engineering, A.C. College of Technology, Anna University \\ Chennai - 600025 , India \\ Tel: 91-44-2220-3515 E-mail: n_nagendra2002@yahoo.com
}

\begin{abstract}
This work presents a comprehensive investigation on the solubility and mass transfer coefficient enhancement of furfural through Hydrotropy. The solubility and mass transfer coefficient studies were carried out using hydrotropes such as urea, tri-sodium citrate, sodium toluate and sodium benzoate under a wide range of hydrotrope concentrations $(0$ to $3.0 \mathrm{~mol} / \mathrm{L}$ ) and different system temperatures ( 303 to $333 \mathrm{~K}$ ). The solubility of furfural increases with increase in hydrotrope concentration and also with system temperature. A Minimum Hydrotrope Concentration (MHC) in the aqueous phase was required to initiate significant solubilization of furfural. Consequent to the increase in solubilization of furfural, the mass transfer coefficient was also found to increase with increase in hydrotrope concentration. A threshold value of MHC is to be maintained to have an appreciable enhancement in the mass transfer coefficient. The maximum enhancement factor, which is the ratio of the value in the presence and absence of a hydrotrope, has been determined for all sets of experimentations. A comprehensive design expert plot for hydrotropic effect on furfural is also presented.The performance of hydrotropes was measured in terms of Setschnew constant $\mathrm{K}_{\mathrm{s}}$ and reported for all hydrotropes used in this study.
\end{abstract}

Keywords: Hydrotropes, Solubilization, Mass transfer co-efficient, Separation, Solubilizers

\section{Introduction}

Hydrotropes are a class of chemical compounds which effect an increased aqueous solubility by several fold to certain solutes which are sparingly soluble in water under normal conditions. This phenomenon termed Hydrotropy can be considered to be a potentially and industrially attractive technique since the observed increase in solubility is much higher than that effected by other solubilization methods. Easy recovery of dissolved solute and possible re-use of hydrotrope solutions makes this method the most attractive one particularly at industrial levels.

Neuberg was the first to report hydrotropy when he dissolved a variety of organic substances, such as carbohydrates, esters, lipids, drugs, fats and oils in aqueous solutions containing hydrotropes. The advantage of certain properties, such as the solvent character being independent of $\mathrm{pH}$, high selectivity, absence of emulsification, inexpensive aqueous phase makes this technique superior to other solubilization methods such as micellar solubilization, miscibility, co-solvency, salting-in, etc. Because of the solubilizing effect of these hydrotropes, the mass transfer coefficient of two-phase systems can considerably be enhanced.

It has been observed that in many two-phase reaction systems involving a sparingly soluble organic compound like furfural, the mass-transfer coefficient was found to be very low solely due to the poor solubility of furfural in the aqueous phase. Since furfural serves as a raw material/intermediate for a wide variety of chemicals and allied products and the separation of furfural from any liquid mixture seems to be difficult, this hydrotropic technique can be adapted to increase the solubility as well as to separate such mixtures effectively. The hydrotropes used in this work are freely soluble in water and practically insoluble in furfural. All are non- reactive and non- toxic and do not produce any temperature effect when dissolved in water. The easy availability and cheapness of hydrotropes are the other factors considered in the selection of hydrotropes. Data on various aspects of hydrotropic study on the solubility and mass-transfer coefficient for furfural -water system are reported for the first time.

\section{Experimental}

All the chemicals used in this work were manufactured by S.D.Finechemicals Pvt. Ltd., with a manufacturer's stated purity of $99 \%$.

Thermostatic bath method was used to determine solubility values. For each solubility test, about $100 \mathrm{ml}$ of furfural previously saturated with distilled water was taken in a separating funnel and $100 \mathrm{ml}$ of a solution of the hydrotrope of known concentration was added. The separating funnel was sealed to avoid evaporation of mixtures at higher temperatures. The solution of different concentrations of the hydrotrope was prepared by dilution with distilled water. The separating funnel was immersed in a constant-temperature bath fitted with a temperature controller which could control the temperature within $\pm 0.1{ }^{\circ} \mathrm{C}$. The setup was kept overnight for equilibration. After equilibrium was attained, 
the aqueous layer was carefully separated from the ester layer and transferred into a beaker. The solute concentration was estimated by the addition of excess $\mathrm{NaOH}$ using a standardized Hcl solution and phenolphthalein as an indicator. All the solubility experiments were conducted in duplicate to check the reproducibility. The observed error was $<2 \%$.

The experimental setup for the determination of the mass-transfer coefficient consisted of a vessel provided with baffles and a turbine impeller run by a motor to agitate the mixture. The speed of the impeller in rpm was selected in such a way to get effective mixing, which was maintained at the same value for all experiments.

The experimental procedure used for the determination of the transport coefficient is a well-adopted one. The vessel used for mass transfer studies is of height $40 \mathrm{~cm}$ and of inner diameter $15 \mathrm{~cm}$. The turbine impeller diameter is $5 \mathrm{~cm}$, the width is $1 \mathrm{~cm}$, and the length is $1.2 \mathrm{~cm}$. It has four blades. The baffle is $40 \mathrm{~cm}$ high with a diameter of $1.5 \mathrm{~cm}$. There are about four baffles that rotate at a speed of $600 \mathrm{rpm}$.For each run to measure the mass-transfer coefficient; $250 \mathrm{ml}$ of the furfural previously saturated with distilled water was added to the hydrotrope solution of known concentration. The sample was then agitated for a known time of 600,1200, 1800, and 2400 seconds. After the end of fixed time $t$, the entire mixture was transferred to a separating funnel. After allowing to stand for some time, the aqueous layer was carefully separated from the furfural layer. The concentration of the solubilized furfural in aqueous hydrotrope solutions at time $t$ was analyzed as done for solubility determinations. A plot of $-\log \left[1-C_{\mathrm{b}} / C^{*}\right]$ versus $t$ is drawn, where $C_{\mathrm{b}}$ is the concentration of solute at time $t$ and $C^{*}$ is the equilibrium solubility of solute at the same hydrotrope concentration. The slope of the graph gives $k_{\mathrm{L}} a / 2.303$, from which $k_{\mathrm{L}} a$, the mass-transfer coefficient was determined. Duplicate runs were made to check the reproducibility. The observed error was $<2 \%$.

\section{Results and discussion}

\subsection{Solubility}

The solubility of the furfural standard in water in the absence of any hydrotrope is $8.12 \times 10^{-3} \mathrm{~mol} / \mathrm{L}$ at $303 \mathrm{~K}(\mathrm{Table} 1)$, compared to $8.32 \times 10^{-3} \mathrm{~mol} / \mathrm{L}$ as reported by Dean (1987). Thus, the solubility values in water are in excellent agreement with the earlier reported values.

Experimental data representing the average of duplicate determinations on the effect of hydrotropes, i.e., urea, tri-sodium citrate, sodium toluate and sodium benzoate on the solubility of furfural are presented in Tables 1-4 and are plotted in Figures 1-4. Urea is one of the hydrotropes used in this study. The solubility of furfural in water at $303 \mathrm{~K}$ in the absence of any hydrotrope is $8.12 \times 10^{-3} \mathrm{~mol} / \mathrm{L}$. It has been observed that the solubility values increase significantly only after the addition of $0.40 \mathrm{~mol} / \mathrm{L}$ of urea in the aqueous phase. This concentration in referred to as Minimum Hydrotrope Concentration (MHC).

Therefore, it is evident that hydrotropic solubilization is displayed only above the MHC, irrespective of system temperature. Hydrotropy does not seem to be operative below the MHC, which may be a characteristic of a particular hydrotrope with respect to each solute. This MHC value assumes greater significance in the context of recovery of hydrotrope solutions. Since hydrotropy appears to operate only at significant concentrations of hydrotrope in water, most hydrotropic solutions release the dissolved solute on dilution with distilled water below MHC. The knowledge of MHC values is necessary especially at industrial levels, as it ensures ready recovery of hydrotrope for reuse. MHC values remained unaltered even at increased system temperatures.

The solubilization effect varies with concentration of hydrotropes (Table 1). In the present case, a clear increasing trend in the solubility of furfural was observed above the MHC of urea. This increasing trend is maintained only up to a certain concentration of urea in the aqueous phase, beyond which there is no appreciable increase in the solubility of furfural. This concentration of citric acid (hydrotrope) in the aqueous phase is referred to as the maximum hydrotrope concentration $\left(C_{\max }\right)$. From the analysis of the experimental data, it is observed that a further increase in hydrotrope concentration beyond $C_{\max }$ does not bring any appreciable increase in the solubility of furfural even up to $3.00 \mathrm{~mol} / \mathrm{L}$ of urea in the aqueous phase. Similar to the MHC values, the $C_{\max }$ values of hydrotropes also remained unaltered with increase in system temperature.

The knowledge of $\mathrm{MHC}$ and $C_{\max }$ values of each hydrotrope with respect to a particular solute assumes greater significance in this study since it indicates the beginning and saturation of the solubilization effect of hydrotropes. The values of $\mathrm{MHC}$ and $C_{\max }$ of a hydrotrope with respect to furfural may be useful in determining the recovery of the solute even to an extent of the calculated amount from hydrotrope solutions at any concentration between $\mathrm{MHC}$ and $C_{\max }$ by simple dilution with distilled water. This is the unique advantage of hydrotropic solubilization technique.

From the experimental data plotted in Figure 1, it can further be observed that, in order to achieve the particular solubility of to say $45 \times 10^{-3} \mathrm{~mol} / \mathrm{L}$, the urea concentration should be $1.70 \mathrm{~mol} / \mathrm{L}$ at $303 \mathrm{~K}, 1.30 \mathrm{~mol} / \mathrm{L}$ at $313 \mathrm{~K}$ and 1.00 $\mathrm{mol} / \mathrm{L}$ at $323 \mathrm{~K}$ in the aqueous phase. Thus it can be seen that as the system temperature increases, the concentration of urea required in the aqueous phase to achieve a particular solubility of furfural decreases. A similar trend has been observed for other systems also. 
In the concentration range of urea between 0.00 and $3.00 \mathrm{~mol} / \mathrm{L}$, three different regions of urea as hydrotrope were observed. It was inactive below MHC value of $0.40 \mathrm{~mol} / \mathrm{L}$, above which an appreciable increase in the solubility of furfural was found up to $2.40 \mathrm{~mol} / \mathrm{Land}$ beyond which there is no further increase in the solubility even upto 3.00 $\mathrm{mol} / \mathrm{L}$.Hence urea was found to be an effective hydrotrope in the concentration range between 0.40 and $2.40 \mathrm{~mol} / \mathrm{L}$ towards furfural. It has also been observed that the solubilization effect of urea was not a linear function of the concentration of the urea solution. The solubilization effect of urea increases with increase in hydrotrope concentration and also with system temperature.

A similar trend has been observed in the solubilization effect of other hydrotropes namely tri-sodium citrate, sodium toluate and sodium benzoate. It has also been observed that the MHC values of hydrotrope used in this work range between 0.40 and $0.60 \mathrm{~mol} / \mathrm{L}$ (Table 5), which seem to depend on the hydrophilicity of a hydrotrope. The $C_{\max }$ values of hydrotropes range between 2.20 and $2.40 \mathrm{~mol} / \mathrm{L}$ (Table 5) in most cases. The highest value of solubilization enhancement factors $\varphi_{s}$, which is the ratio of solubility values in the presence and absence of a hydrotrope has been observed in the case of urea as 8.05 at a system temperature of $333 \mathrm{~K}$ (Table 6).

\subsection{Mass-Transfer Coefficient}

The mass-transfer coefficient of furfural + water system in the absence of any hydrotrope was determined as $6.56 \times 10^{-5}$ $\mathrm{s}^{-1}$ at $303 \mathrm{~K}$ (Table 7). The effect of different hydrotropes on the mass-transfer coefficient of furfural at different hydrotrope concentrations is also given in the same table. It can be seen that a threshold value of $0.40 \mathrm{~mol} / \mathrm{L}$ is required to effect significant enhancement in the mass transfer coefficient of furfural + water system, as was observed in the case of solubility determinations. The mass-transfer coefficient of furfural + water system increases with increase in urea concentration. The maximum enhancement factor for mass-transfer coefficient of furfural + water system in the presence of urea was found to be 7.83(Table 7). A similar trend in the mass-transfer coefficient enhancement ( $\varphi_{\mathrm{mtc}}$ of furfural has been observed for other hydrotropes also namely tri-sodium citrate, sodium toluate and sodium benzoate. The highest value of $\varphi_{\mathrm{mtc}}(8.37)$ has been observed in the presence of urea as hydrotrope at $\mathrm{Cmax}$ of $3.00 \mathrm{~mol} / \mathrm{L}$.

Data on hydrotropic study for furfural has been provided using a comprehensive design expert plot for the first time in literature.(fig .5)

\subsection{Effectiveness of hydrotropes}

The effectiveness factor of each hydrotrope with respect to furfural at different system temperatures has been determined by analyzing the experimental solubility data for each case applying the model suggested by Setschenow (1951) and later modified by Pathak and Gaikar (1992), as given by the equation

$$
\left.\log \left[S / S_{\mathrm{m}}\right]\right)=K_{\mathrm{s}}\left[C_{\mathrm{s}}-C_{\mathrm{m}}\right]
$$

Where $S$ and $S_{\mathrm{m}}$ are the solubility of furfural at any hydrotrope concentration $C_{\mathrm{s}}$ and the minimum hydrotrope concentration $C_{\mathrm{m}}$, (same as $\mathrm{MHC}$ ) respectively. The Setschenow constant $K_{\mathrm{s}}$ can be considered as a measure of the effectiveness of a hydrotrope at any given conditions of hydrotrope concentration and system temperature. The Setschenow constant values for hydrotropes namely urea, tri-sodium citrate, sodium toluate and sodium benzoate for furfural + water system at different system temperatures are listed in Table 8 . The highest value has been observed as 0.452 in the case of urea as hydrotrope at $333 \mathrm{~K}$.

\section{Conclusions}

The solubility of furfural which is practically insoluble in water has been increased to a maximum value of 8.05 in the presence of urea as hydrotrope with a corresponding increase in the mass transfer coefficient..Hydrotropic study on furfural is given using a comprehensive design expert plot. This would be much useful in increasing the rate of output of the desired product made from furfural. The MHC and $C_{\max }$ values of the hydrotrope with respect to furfural can be used for the recovery of the dissolved furfural and hydrotrope solutions at any hydrotrope concentration between MHC and $C_{\max }$ by simple dilution with distilled water. This will eliminate the huge cost and energy normally involved in the separation of the solubilized solute from its solution. The unprecedent increase in the solubilizing effect of hydrotropes may be attributed to the formation of organized aggregates of hydrotrope molecules at a particular concentration.

\section{References}

A. Pandit \& M. M. Sharma. (1987). Intensification of heterogeneous reactions through hydrotropy.Alkaline hydrolysis of esters and oximation of cyclododecanone. Chem. Eng. Sci. 42, 2519-2523.

A.A.Badwan, L.K. El-Khordagui \& A.M. Saleh. (1983).The solubility of Benzodiazepines In Sodium Saicylate solutions and A Proposed mechanism for hydrotropic Solubilisation.Int.J. Pharm. 13, 67-74.

Akhilesh Kumar Jain. (2008). reSolubilization of indomethacin using hydrotropes for aqueous injection European. Journal of Pharmaceutics and Biopharmaceutics, Volume 68, Issue 3, 701-714. 
B.Janakiraman \& M.M. Sharma. (1985). Enhancing rates of multi phase reactions through hydrotropy. Chem. Eng. Sci. 40, 2156-2158.

Badwan et al. (1982). The Solubility of Benzodiazepines in Sodium Salicylate Solutions and a Proposed Mechanism for Hydrotropic Solubilization. Int. J. Pharm. 13, 67-74.

C. Neuberg. (1916). Hydrotropy. Biochem. Z. 76: 107-108.

C.Isabel, Rigoli, C.Carla, Schmitt, \& G. Miguel Neumann,( 2007). The hydrotrope effect on the photopolymerization of styrenesulfonate initiated by Ru complexes. Journal of Photochemistry and Photobiology A. Chemistry, 188, Issues 2-3, 20. 329-333.

Colonia et al. (1998). Phase Relations of oand $p$ Chlorobenzoic Acids in Hydrotrope Solutions. J. Chem. Eng. Data. 43, 220-225.

D. Balasubramanian, V. Srinivas, V. G. Gaikar, \& M...M..Sharma. ( 1989). Aggregation Behavior of Hydrotropes in Aqueous Solutions, J. Phys. Chem., 93, 3865-3870.

Friberg et al. (1996). Reversible Extraction Process of Phenyl Ethyl Alcohol, a Fragrance. Ind. Eng. Chem. Res. 35, 2856-2859.

K. Travis, Hodgdon, \& Eric W. Kaler. (2007). Hydrotropic solutions, Current Opinion in Colloid \& Interface Science, Volume 12, 3,121-128.

M. Agarwal \& V.G. Gaikar. (1992). Extractive Separation Using Hydrotropes. Sep. Technol. 2, 79-84.

M. Laxman, M. M. Sharma. (1990). Reduction of Isophorone with Borohydride: Change in Regio Selectivity with Hydrotropes. Synth. Commun. 20, 111-117.

Mahapatra et al.. (1988). New Strategies in Extractive Distillation; Use of Aqueous Solution of Hydrotropes and Organic Bases as Solvent for Organic Acids. Sep. Sci. Technol. 23, 429-436.

N. Nagendra Gandhi \& M. Dharmendira Kumar. (2000). Effect of Hydrotropes on Solubility and Mass Transfer Coefficient of Amyl Acetate. Bioprocess Eng. 449/0116.

N. Nagendra Gandhi \& N. Meyyappan. (2004). Solubility and Mass Transfer Coefficient Enhancement of Benzyl Acetate in Water through Hydrotropy. J. Chem. Eng. Data, 49, 1290-1294.

N. Nagendra Gandhi \& N. Meyyappan. (2004). Solubility and Mass Transfer Coefficient Enhancement of Benzyl Acetate in Water through Hydrotropy. J. Chem. Eng. Data.,49. 1290-1294.

N. Nagendra Gandhi \& N. Meyyappan. (2005). Solubility and Mass Transfer Coefficient Enhancement of Benzyl Benzoate in Water through Hydrotropy. J. Chem. Eng. Data 50, 796-800.

N. Nagendra Gandhi \& N. Meyyappan. (2005). Solubility and Mass Transfer Coefficient Enhancement of Benzyl Benzoate in Water through Hydrotropy. J. Chem. Eng. Data. 50, 796-800.

N.Nagendra Gandhi \& M. Dharmendira Kumar. (2000). Effect of Hydrotropes on Solubility and Mass Transfer Coefficient of Methyl Salicylate. J. Chem. Eng. Data 45, 419-423.

Nagendra Gandhi et al. (1998). Solubility and Mass Transfer Coefficient Enhancement of Ethyl Benzoate through Hydrotropy. Hungarian J. Ind. Chem. 1998, 26, 63-68.

Nagendra Gandhi et al.. (1998). Effect of Hydrotropes on Solubility and Mass-Transfer Coefficient of Butyl Acetate. $J$. Chem. Eng.Data. 43, 695-699.

P. O Raynaud-Lacroze \& N. S. Tavare. (1993). Separation of 2-naphthol: Hydrotropy and Precipitation. Ind. Eng. Chem. Res.32, 685-691.

S. Barbosa, P. Taboada, E. Castro \& V. Mosquera. (2006). Influence of SDS and two anionic hydrotropes on the micellized state of the triblock copolymer E71G7E71, J Colloid Interface Sci. 296, 677-684.

S.E. Friberg \& C. Brancewicz. (1994). O/W Microemulsions and Hydrotropes: The Coupling Action of a Hydrotrope. Langmuir. 10, 2945-2949.

Sara Nicoli, Franca Zani, Stefania Bilzi, Ruggero Bettini\& Patrizia Santi. (2008). Association of nicotinamide with parabens: Effect on solubility, partition and transdermal permeation European Journal of Pharmaceutics and Biopharmaceutics, Volume 69, Issue 2, 613-621.

V. Deepak, Dandekar, G.K. Jayaprakasha, Bhimanagouda S. Patil. (2008). Hydrotropic extraction of bioactive limonin from sour orange (Citrus aurantium L.) seeds Food Chemistry, Volume 109, Issue 3, 515-520.

V.G. Gaikar. \& P.V. Phatak. (1999). Selective Solubilisation of Isomers in Hydrotrope Solution o-/p-Chlorobenzoic acids and o-/p- Nitro anilines. Sep. Sci. Technol. 34, 439-459. 
X. Chen \& J.C. Micheu. ( 2002). Hydrotropes Induced Auto Catalysis in the Biphasic Alkaline Hydrolysis of Aromatic Esters. J. Colloid Interface Sci. 249, 172-179.

Table 1. Effect of urea concentration (C) on the solubility $(\mathrm{S})$ of furfural in water

\begin{tabular}{|c|c|c|c|c|c|}
\hline \multirow[t]{2}{*}{ S.No. } & \multirow[t]{2}{*}{$\mathrm{C}, \mathrm{mol} / \mathrm{L}$} & \multicolumn{4}{|c|}{$10^{3} \mathrm{~S}, \mathrm{~mol} / \mathrm{L}$} \\
\hline & & $\mathrm{T}=303 \mathrm{~K}$ & $\mathrm{~T}=313 \mathrm{~K}$ & $\mathrm{~T}=323 \mathrm{~K}$ & $\mathrm{~T}=333 \mathrm{~K}$ \\
\hline 1 & 0.00 & 8.12 & 8.36 & 8.92 & 9.17 \\
\hline 2 & 0.10 & 8.48 & 8.67 & 9.15 & 9.33 \\
\hline 3 & 0.20 & 8.75 & 8.93 & 9.56 & 9.82 \\
\hline 4 & 0.30 & 8.92 & 9.32 & 9.81 & 10.35 \\
\hline 5 & 0.40(MHC) & 9.97 & 10.45 & 10.98 & 11.38 \\
\hline 6 & 0.50 & 12.43 & 13.24 & 16.35 & 25.31 \\
\hline 7 & 0.60 & 14.65 & 18.46 & 23.98 & 33.87 \\
\hline 8 & 0.70 & 17.34 & 22.67 & 30.19 & 41.96 \\
\hline 9 & 0.80 & 20.86 & 25.39 & 36.71 & 47.38 \\
\hline 10 & 0.90 & 22.43 & 30.83 & 41.58 & 53.42 \\
\hline 11 & 1.00 & 25.75 & 34.49 & 46.25 & 58.97 \\
\hline 12 & 1.10 & 28.92 & 38.51 & 50.49 & 63.43 \\
\hline 13 & 1.20 & 31.35 & 42.78 & 54.45 & 68.19 \\
\hline 14 & 1.30 & 34.16 & 46.12 & 58.64 & 72.62 \\
\hline 15 & 1.40 & 37.45 & 50.34 & 62.36 & 75.24 \\
\hline 16 & 1.50 & 40.78 & 53.98 & 65.58 & 78.63 \\
\hline 17 & 1.60 & 43.53 & 56.72 & 69.72 & 81.32 \\
\hline 18 & 1.70 & 46.14 & 59.58 & 72.64 & 83.49 \\
\hline 19 & 1.80 & 50.38 & 62.36 & 74.92 & 85.17 \\
\hline 20 & 1.90 & 52.64 & 64.15 & 75.35 & 86.32 \\
\hline 21 & 2.00 & 54.73 & 66.78 & 77.49 & 88.61 \\
\hline 22 & 2.20 & 57.12 & 68.26 & 79.29 & 90.28 \\
\hline 23 & $2.40\left(C_{\max }\right)$ & 58.25 & 69.32 & 80.41 & 91.63 \\
\hline 24 & 2.60 & 58.26 & 69.33 & 80.42 & 91.64 \\
\hline 25 & 2.80 & 58.27 & 69.34 & 80.43 & 91.65 \\
\hline 26 & 3.00 & 58.28 & 69.35 & 80.44 & 91.66 \\
\hline
\end{tabular}


Table 2. Effect of tri-sodium citrate concentration (C) on the solubility $(\mathrm{S})$ of furfural in water

\begin{tabular}{|c|c|c|c|c|c|}
\hline \multirow[b]{2}{*}{ S.No. } & \multirow{2}{*}{$\mathrm{C}, \mathrm{mol} / \mathrm{L}$} & \multicolumn{4}{|c|}{$10^{3} \mathrm{~S}, \mathrm{~mol} / \mathrm{L}$} \\
\hline & & $\mathrm{T}=303 \mathrm{~K}$ & $\mathrm{~T}=313 \mathrm{~K}$ & $\mathrm{~T}=323 \mathrm{~K}$ & $\mathrm{~T}=333 \mathrm{~K}$ \\
\hline 1 & 0.00 & 8.12 & 8.36 & 8.92 & 9.17 \\
\hline 2 & 0.10 & 8.41 & 8.67 & 9.08 & 9.33 \\
\hline 3 & 0.20 & 8.63 & 8.96 & 9.47 & 9.82 \\
\hline 4 & 0.30 & 8.75 & 9.32 & 9.76 & 10.34 \\
\hline 5 & 0.40(МНС) & 9.82 & 10.31 & 10.84 & 11.23 \\
\hline 6 & 0.50 & 11.36 & 13.24 & 16.69 & 25.61 \\
\hline 7 & 0.60 & 13.49 & 18.46 & 23.18 & 31.64 \\
\hline 8 & 0.70 & 15.69 & 22.53 & 30.79 & 37.32 \\
\hline 9 & 0.80 & 18.74 & 25.62 & 35.34 & 42.47 \\
\hline 10 & 0.90 & 21.62 & 28.29 & 39.12 & 48.64 \\
\hline 11 & 1.00 & 23.15 & 31.73 & 44.68 & 53.39 \\
\hline 12 & 1.10 & 25.38 & 34.86 & 47.46 & 56.28 \\
\hline 13 & 1.20 & 28.65 & 38.93 & 50.39 & 60.85 \\
\hline 14 & 1.30 & 30.81 & 41.59 & 54.86 & 64.69 \\
\hline 15 & 1.40 & 32.25 & 45.78 & 56.45 & 68.15 \\
\hline 16 & 1.50 & 35.53 & 48.54 & 59.74 & 71.62 \\
\hline 17 & 1.60 & 37.66 & 51.83 & 61.78 & 73.53 \\
\hline 18 & 1.70 & 39.29 & 52.38 & 63.91 & 75.42 \\
\hline 19 & 1.80 & 41.58 & 54.52 & 65.39 & 76.86 \\
\hline 20 & 1.90 & 42.67 & 55.26 & 65.87 & 77.41 \\
\hline 21 & 2.00 & 43.25 & 55.84 & 66.25 & 77.65 \\
\hline 22 & 2.20 & 45.12 & 56.21 & 67.04 & 78.28 \\
\hline 23 & $2.40\left(C_{\max }\right)$ & 46.73 & 57.28 & 68.19 & 79.34 \\
\hline 24 & 2.60 & 46.74 & 57.29 & 68.21 & 79.35 \\
\hline 25 & 2.80 & 46.75 & 57.31 & 68.22 & 79.36 \\
\hline 26 & 3.00 & 46.76 & 57.32 & 68.23 & 79.37 \\
\hline
\end{tabular}


Table 3. Effect of tri-sodium citrate concentration (C) on the solubility (S) of furfural in water

\begin{tabular}{|c|c|c|c|c|c|}
\hline \multirow[b]{2}{*}{ S.No. } & \multirow{2}{*}{$\mathrm{C}, \mathrm{mol} / \mathrm{L}$} & \multicolumn{4}{|c|}{$10^{3} \mathrm{~S}, \mathrm{~mol} / \mathrm{L}$} \\
\hline & & $\mathrm{T}=303 \mathrm{~K}$ & $\mathrm{~T}=313 \mathrm{~K}$ & $\mathrm{~T}=323 \mathrm{~K}$ & $\mathrm{~T}=333 \mathrm{~K}$ \\
\hline 1 & 0.00 & 8.12 & 8.36 & 8.92 & 9.17 \\
\hline 2 & 0.10 & 8.37 & 8.52 & 9.05 & 9.28 \\
\hline 3 & 0.20 & 8.51 & 8.86 & 9.21 & 9.75 \\
\hline 4 & 0.30 & 8.63 & 9.15 & 9.86 & 10.63 \\
\hline 5 & $0.40(\mathrm{MHC})$ & 8.74 & 9.24 & 10.22 & 11.12 \\
\hline 6 & 0.50 & 8.82 & 9.45 & 11.04 & 12.48 \\
\hline 7 & 0.60 & 9.71 & 10.82 & 12.05 & 13.57 \\
\hline 8 & 0.70 & 11.34 & 13.23 & 16.37 & 21.36 \\
\hline 9 & 0.80 & 13.52 & 16.76 & 20.46 & 26.45 \\
\hline 10 & 0.90 & 15.41 & 19.58 & 23.17 & 31.38 \\
\hline 11 & 1.00 & 17.63 & 21.92 & 27.57 & 36.87 \\
\hline 12 & 1.10 & 18.29 & 24.59 & 30.37 & 40.39 \\
\hline 13 & 1.20 & 20.47 & 26.31 & 33.48 & 44.88 \\
\hline 14 & 1.30 & 22.68 & 29.44 & 36.77 & 48.84 \\
\hline 15 & 1.40 & 23.79 & 32.52 & 40.94 & 50.91 \\
\hline 16 & 1.50 & 25.48 & 34.64 & 43.23 & 53.23 \\
\hline 17 & 1.60 & 27.51 & 35.36 & 45.49 & 55.24 \\
\hline 18 & 1.70 & 28.84 & 37.43 & 47.36 & 57.79 \\
\hline 19 & 1.80 & 29.38 & 38.24 & 49.83 & 59.73 \\
\hline 20 & 1.90 & 30.24 & 39.73 & 50.63 & 61.46 \\
\hline 21 & 2.00 & 31.09 & 40.15 & 51.26 & 62.25 \\
\hline 22 & 2.20 & 32.12 & 41.23 & 52.44 & 63.48 \\
\hline 23 & $2.40\left(C_{\max }\right)$ & 32.13 & 41.24 & 52.45 & 63.49 \\
\hline 24 & 2.60 & 32.14 & 41.25 & 52.46 & 63.51 \\
\hline 25 & 2.80 & 32.15 & 41.26 & 52.47 & 63.52 \\
\hline 26 & 3.00 & 32.16 & 41.27 & 52.48 & 63.53 \\
\hline
\end{tabular}


Table 4. Effect of sodium benzoate concentration (C) on the solubility (S) of furfural in water

\begin{tabular}{|c|c|c|c|c|c|}
\hline \multirow[b]{2}{*}{ S.No. } & \multirow{2}{*}{$\mathrm{C}, \mathrm{mol} / \mathrm{L}$} & \multicolumn{4}{|c|}{$10^{3} \mathrm{~S}, \mathrm{~mol} / \mathrm{L}$} \\
\hline & & $\mathrm{T}=303 \mathrm{~K}$ & $\mathrm{~T}=313 \mathrm{~K}$ & $\mathrm{~T}=323 \mathrm{~K}$ & $\mathrm{~T}=333 \mathrm{~K}$ \\
\hline 1 & 0.00 & 8.12 & 8.36 & 8.92 & 9.17 \\
\hline 2 & 0.10 & 8.23 & 8.47 & 9.03 & 9.33 \\
\hline 3 & 0.20 & 8.31 & 8.75 & 9.17 & 9.82 \\
\hline 4 & 0.30 & 8.37 & 8.94 & 9.68 & 10.34 \\
\hline 5 & 0.40 & 8.41 & 9.13 & 10.29 & 11.05 \\
\hline 6 & 0.50 & 8.48 & 9.21 & 10.58 & 11.76 \\
\hline 7 & 0.60 (MHC) & 9.53 & 10.29 & 11.72 & 12.87 \\
\hline 8 & 0.70 & 10.26 & 13.53 & 16.53 & 19.59 \\
\hline 9 & 0.80 & 11.67 & 15.16 & 18.18 & 23.53 \\
\hline 10 & 0.90 & 12.25 & 16.35 & 20.39 & 26.36 \\
\hline 11 & 1.00 & 13.16 & 18.48 & 23.76 & 29.42 \\
\hline 12 & 1.10 & 14.07 & 20.84 & 25.59 & 32.71 \\
\hline 13 & 1.20 & 15.31 & 22.13 & 28.35 & 35.48 \\
\hline 14 & 1.30 & 16.23 & 23.48 & 31.62 & 37.89 \\
\hline 15 & 1.40 & 17.14 & 25.78 & 32.41 & 40.75 \\
\hline 16 & 1.50 & 18.21 & 27.32 & 34.83 & 41.95 \\
\hline 17 & 1.60 & 19.12 & 28.76 & 37.59 & 45.56 \\
\hline 18 & 1.70 & 20.54 & 30.86 & 38.34 & 46.38 \\
\hline 19 & 1.80 & 20.86 & 31.54 & 39.86 & 48.27 \\
\hline 20 & 1.90 & 21.69 & 32.75 & 40.28 & 49.65 \\
\hline 21 & 2.00 & 22.31 & 33.48 & 42.14 & 51.25 \\
\hline 22 & $2.20\left(C_{\max }\right)$ & 23.48 & 34.59 & 43.23 & 52.41 \\
\hline 23 & 2.40 & 23.49 & 34.6 & 43.24 & 52.42 \\
\hline 24 & 2.60 & 23.5 & 34.61 & 43.25 & 52.43 \\
\hline 25 & 2.80 & 23.51 & 34.62 & 43.26 & 52.44 \\
\hline 26 & 3.00 & 23.52 & 34.63 & 43.27 & 52.45 \\
\hline
\end{tabular}


Table 5. MHC and Cmax values of Hydrotropes

\begin{tabular}{|c|l|l|l|}
\hline No. & Hydrotrope & MHC, $\mathrm{mol} / \mathrm{L}$ & $\mathrm{C}_{\max }, \mathrm{mol} / \mathrm{L}$ \\
\hline 1 & Urea & 0.40 & 2.40 \\
\hline 2 & Tri-Sodium Citrate & 0.40 & 2.40 \\
\hline 3 & Sodium Toluate & 0.60 & 2.20 \\
\hline 4 & Sodium Benzoate & 0.60 & 2.20 \\
\hline
\end{tabular}

Table 6. Maximum solubilisation enhancement factor of ( $\varphi s)$ furfural

\begin{tabular}{|c|l|l|l|l|l|}
\hline \multirow{2}{*}{ No. } & \multirow{2}{*}{ Hydrotrope } & \multicolumn{4}{|c|}{ Maximum enhancement factor for solubility $\left(\varphi_{\mathrm{S}}\right)$} \\
\cline { 3 - 6 } & $\mathrm{T}=303 \mathrm{~K}$ & $\mathrm{~T}=313 \mathrm{~K}$ & $\mathrm{~T}=323 \mathrm{~K}$ & $\mathrm{~T}=333 \mathrm{~K}$ \\
\hline 1 & Urea & 5.84 & 6.63 & 7.32 & 8.05 \\
\hline 2 & Tri-Sodium Citrate & 4.75 & 5.55 & 6.38 & 7.06 \\
\hline 3 & Sodium Toluate & 3.30 & 3.81 & 4.35 & 5.26 \\
\hline 4 & Sodium Benzoate & 2.46 & 3.36 & 3.68 & 4.07 \\
\hline
\end{tabular}


Table 7. Effect of hydrotrope concentration $(C)$ on the mass transfer co-efficient $\left(\mathrm{k}_{\mathrm{L}} \mathrm{a}\right)$ of furfural

\begin{tabular}{|c|c|c|c|c|}
\hline No. & Hydrotrope & $\mathrm{C}, \mathrm{mol} / \mathrm{L}$ & $\begin{array}{c}\mathrm{k}_{\mathrm{La}} \\
10^{5} \mathrm{~s}^{-1}\end{array}$ & $\begin{array}{l}\text { Enhancement factor } \\
\text { for Mass Transfer } \\
\text { Coefficient } \\
\left(\varphi_{\mathrm{mtc}}\right)\end{array}$ \\
\hline \multirow[t]{16}{*}{1} & \multirow[t]{16}{*}{ Urea } & 0.00 & 6.56 & - \\
\hline & & 0.20 & 7.25 & 1.10 \\
\hline & & $0.40(\mathrm{MHC})$ & 10.64 & 1.62 \\
\hline & & 0.60 & 15.28 & 2.32 \\
\hline & & 0.80 & 22.83 & 3.48 \\
\hline & & 1.00 & 28.46 & 4.33 \\
\hline & & 1.20 & 33.52 & 5.10 \\
\hline & & 1.40 & 39.34 & 5.99 \\
\hline & & 1.60 & 41.65 & 6.34 \\
\hline & & 1.80 & 46.95 & 7.15 \\
\hline & & 2.00 & 48.36 & 7.37 \\
\hline & & 2.20 & 50.59 & 7.71 \\
\hline & & $2.40\left(\mathrm{C}_{\max }\right)$ & 51.43 & 7.83 \\
\hline & & 2.60 & 52.38 & 7.98 \\
\hline & & 2.80 & 53.81 & 8.20 \\
\hline & & 3.00 & 54.94 & 8.37 \\
\hline \multirow[t]{16}{*}{2} & \multirow[t]{16}{*}{ Tri-Sodium Citrate } & 0.00 & 6.56 & - \\
\hline & & 0.20 & 7.15 & 1.08 \\
\hline & & $0.40(\mathrm{MHC})$ & 9.32 & 1.42 \\
\hline & & 0.60 & 13.86 & 2.11 \\
\hline & & 0.80 & 19.54 & 2.97 \\
\hline & & 1.00 & 25.68 & 3.91 \\
\hline & & 1.20 & 30.42 & 4.63 \\
\hline & & 1.40 & 36.84 & 5.61 \\
\hline & & 1.60 & 38.57 & 5.87 \\
\hline & & 1.80 & 39.75 & 6.05 \\
\hline & & 2.00 & 40.34 & 6.14 \\
\hline & & 2.20 & 41.29 & 6.29 \\
\hline & & $2.40\left(\mathrm{C}_{\max }\right)$ & 42.64 & 6.50 \\
\hline & & 2.60 & 43.52 & 6.63 \\
\hline & & 2.80 & 43.91 & 6.69 \\
\hline & & 3.00 & 44.28 & 6.75 \\
\hline
\end{tabular}




\begin{tabular}{|c|c|c|c|c|}
\hline \multicolumn{5}{|l|}{3} \\
\hline & \multirow[t]{16}{*}{ Sodium Toluate } & 0.00 & 6.56 & - \\
\hline & & 0.20 & 7.09 & 1.08 \\
\hline & & 0.40 & 8.54 & 1.30 \\
\hline & & $0.60(\mathrm{MHC})$ & 10.67 & 1.62 \\
\hline & & 0.80 & 13.42 & 2.04 \\
\hline & & 1.00 & 15.48 & 2.35 \\
\hline & & 1.20 & 18.63 & 2.83 \\
\hline & & 1.40 & 20.27 & 3.08 \\
\hline & & 1.60 & 21.48 & 3.27 \\
\hline & & 1.80 & 23.56 & 3.59 \\
\hline & & 2.00 & 25.49 & 3.88 \\
\hline & & $2.20\left(\mathrm{C}_{\max }\right)$ & 27.64 & 4.21 \\
\hline & & 2.40 & 28.25 & 4.30 \\
\hline & & 2.60 & 29.53 & 4.51 \\
\hline & & 2.80 & 30.48 & 4.64 \\
\hline & & 3.00 & 31.69 & 4.83 \\
\hline \multirow[t]{16}{*}{4} & \multirow[t]{16}{*}{ Sodium Benzoate } & 0.00 & 6.56 & - \\
\hline & & 0.20 & 6.82 & 1.03 \\
\hline & & 0.40 & 7.69 & 1.17 \\
\hline & & $0.60(\mathrm{MHC})$ & 8.43 & 1.28 \\
\hline & & 0.80 & 9.12 & 1.39 \\
\hline & & 1.00 & 9.85 & 1.50 \\
\hline & & 1.20 & 10.46 & 1.59 \\
\hline & & 1.40 & 11.29 & 1.72 \\
\hline & & 1.60 & 12.23 & 1.86 \\
\hline & & 1.80 & 13.49 & 2.05 \\
\hline & & 2.00 & 14.64 & 2.23 \\
\hline & & $2.20\left(\mathrm{C}_{\max }\right)$ & 15.58 & 2.37 \\
\hline & & 2.40 & 17.32 & 2.64 \\
\hline & & 2.60 & 18.49 & 2.81 \\
\hline & & 2.80 & 20.62 & 3.14 \\
\hline & & 3.00 & 21.58 & 3.28 \\
\hline
\end{tabular}


Table 8. Setschenow constant values (ks) of hydrotropes with respect to furfural

\begin{tabular}{|c|l|l|l|l|l|}
\hline \multirow{2}{*}{ No. } & \multirow{2}{*}{ Hydrotrope } & \multicolumn{4}{|c|}{ Setschenow Constant $\left(\mathrm{K}_{\mathrm{S}}\right)$} \\
\cline { 3 - 6 } & & $\mathrm{T}=303 \mathrm{~K}$ & $\mathrm{~T}=313 \mathrm{~K}$ & $\mathrm{~T}=323 \mathrm{~K}$ & $\mathrm{~T}=333 \mathrm{~K}$ \\
\hline 1 & Urea & 0.383 & 0.410 & 0.432 & 0.452 \\
\hline 2 & Tri-Sodium Citrate & 0.338 & 0.372 & 0.402 & 0.424 \\
\hline 3 & Sodium Toluate & 0.324 & 0.363 & 0.399 & 0.418 \\
\hline 4 & Sodium Benzoate & 0.244 & 0.329 & 0.354 & 0.381 \\
\hline
\end{tabular}

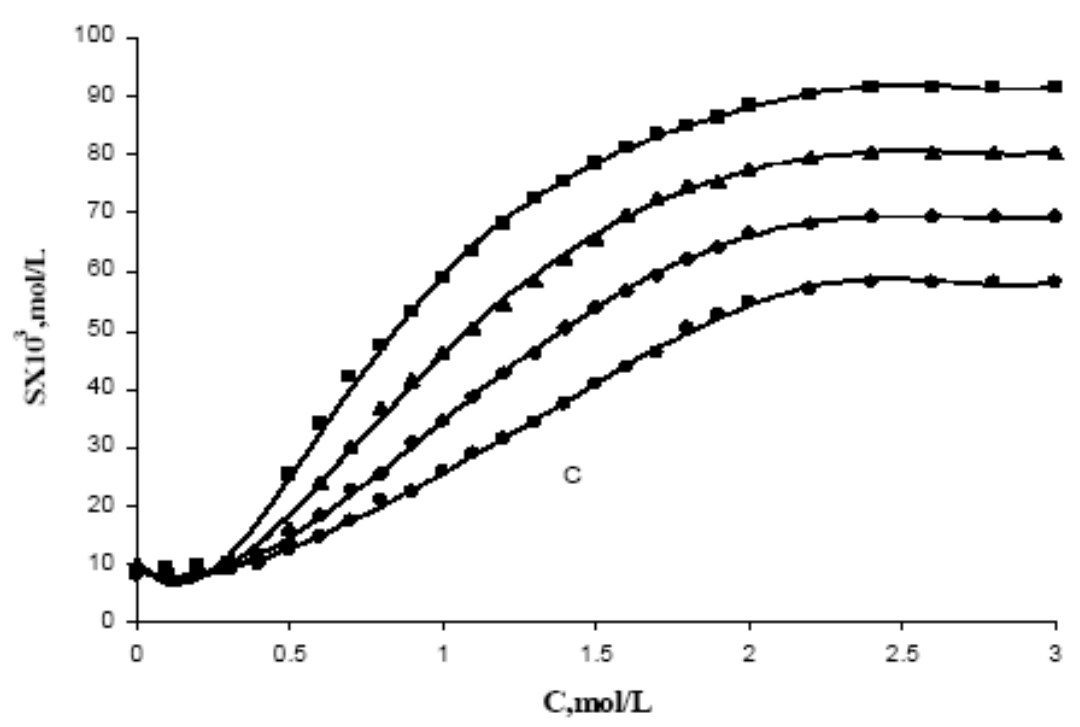

Figure 1. Effect of urea concentration (C) on the solubility (S) of furfural

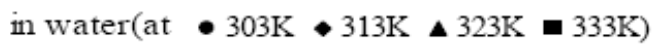

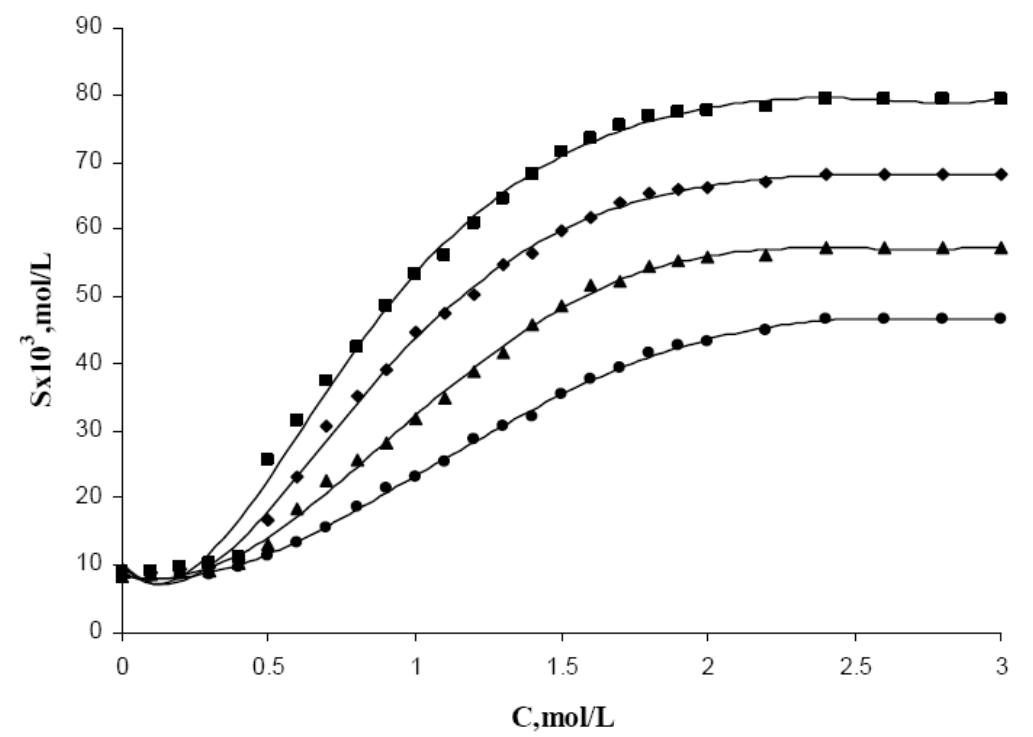

Figure 2. Effect of tri-sodium citrate concentration (C) on the solubility (S) of furfural in water (at • $303 \mathrm{~K} \quad \boldsymbol{\Delta} 313 \mathrm{~K} \bullet 323 \mathrm{~K}$ 


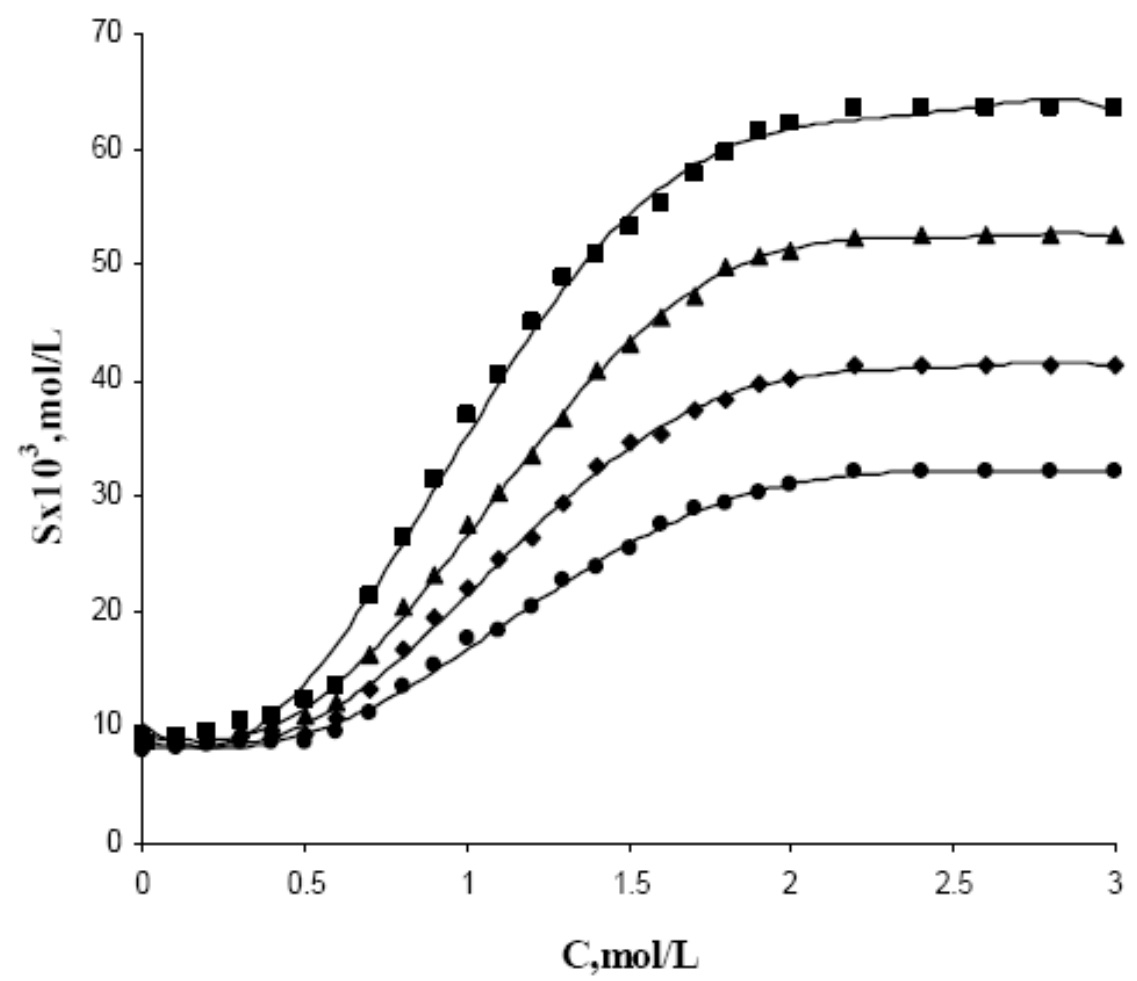

Figure 3. Effect of sodium toluate concentration (C) on the solubility (S) of furfural in water (at • $303 \mathrm{~K} \bullet 313 \mathrm{~K} \Delta 323 \mathrm{~K}$ - $333 \mathrm{~K}$ )

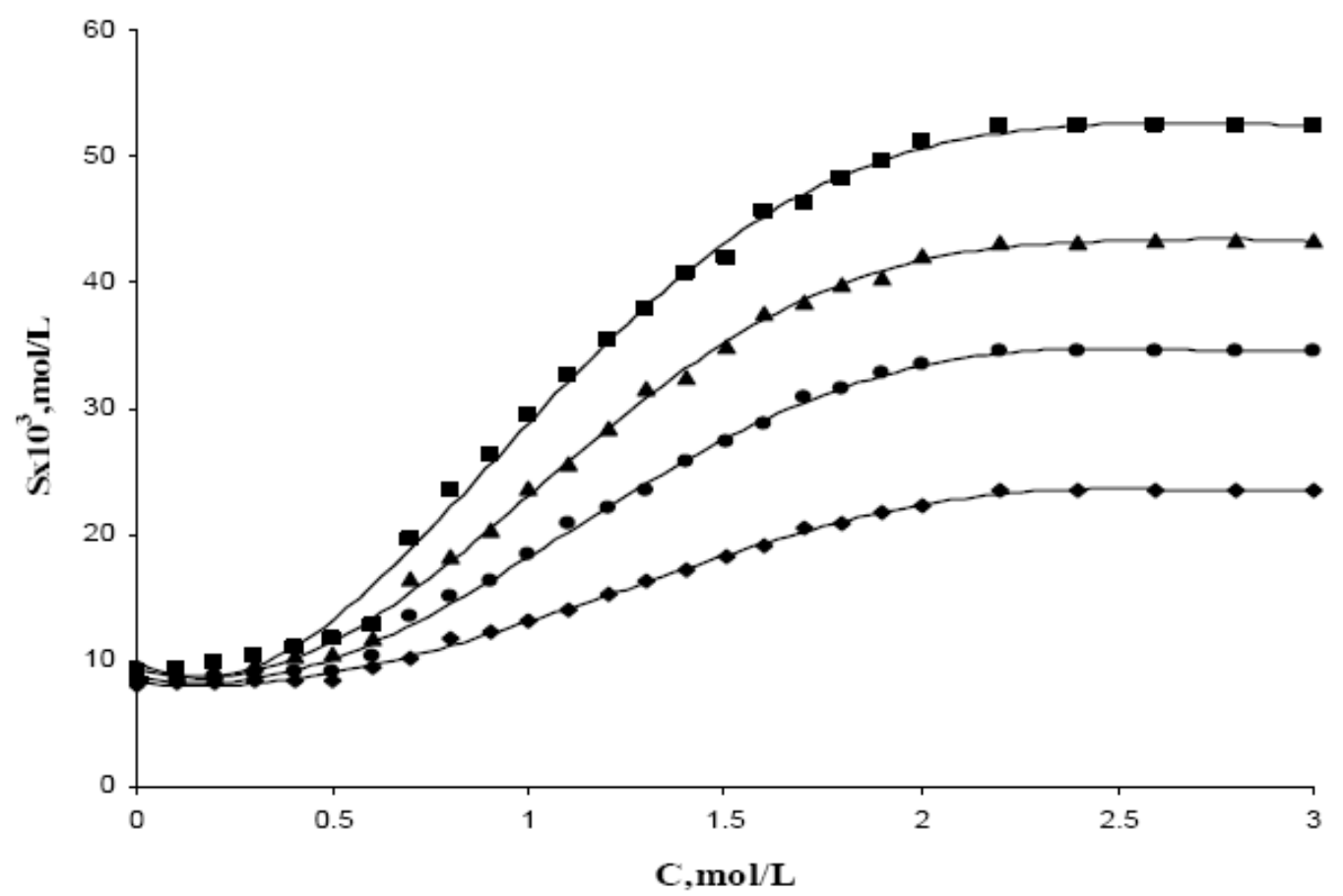

Figure 4. Effect of sodium benzoate concentration (C) on the solubility (S) of furfural in water (at • $303 \mathrm{~K} \bullet 313 \mathrm{~K} \boldsymbol{\Delta} 323 \mathrm{~K}$ - $333 \mathrm{~K}$ ) 


\section{DESIGN-EXPERT Plot}

\section{StdErr of Design}

$X=A$ : urea concentration (C)

$Y=B:$ Effect of urea concentration

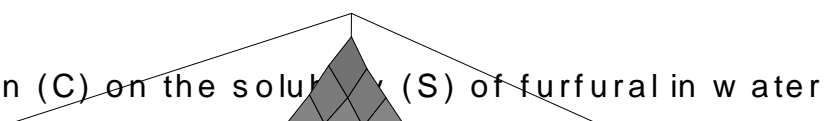

Actual Factors $\quad 0.211155^{\circ}$

C: tri-sodium citrate concentration $(C)=1.50$

D: Effect of tri-sodium.coitrasté oncentration

E: sodium toluate concentratio

$\mathrm{F}$ : Effect of sodium toquate

G: sodium benzoate concentratio

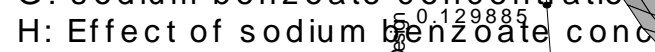

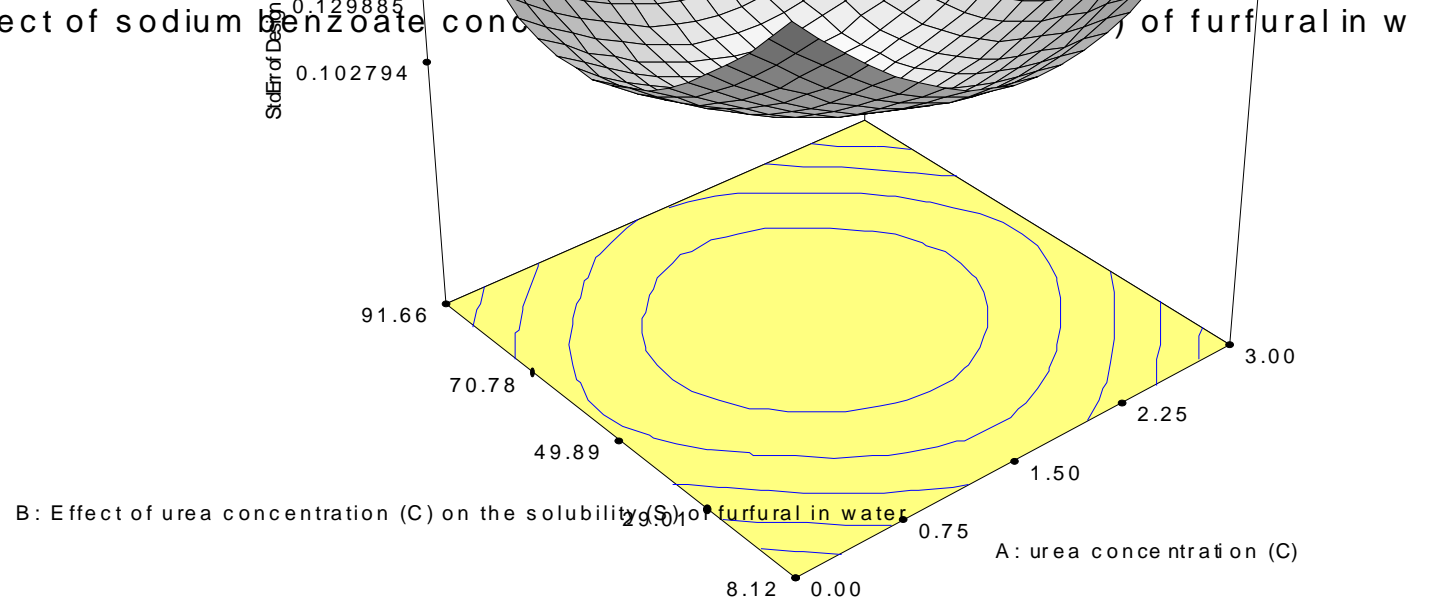

Figure 5. Effect of hydrotrope concentration (C) on the solubility (S), on the mass transfer co-efficient $\left(\mathrm{k}_{\mathrm{L}} \mathrm{a}\right)$, Enhancement factor for mass transfer coefficient $(\varphi m t c)$ of furfural in water. 